\title{
Optimization of a GF-AAS method for lead testing in blood and urine: A useful tool in acute abdominal pain management in emergency
}

\author{
MIHAIL SILVIU TUDOSIE ${ }^{1,2}$, GENICA CARAGEA $^{3}$, DRAGOS MARIAN POPESCU ${ }^{4}$, \\ OANA AVRAM $^{1,2}$, DRAGOS SERBAN ${ }^{1,5}$, CATALIN GABRIEL SMARANDACHE ${ }^{1,5}$, CORNELIU TUDOR $^{5}$, \\ CRISTINEL DUMITRU BADIU ${ }^{1,6}$, BOGDAN SOCEA ${ }^{1,7}$, ALEXANDRU DAN SABAU $^{8}$, MEDA COMANDASU ${ }^{5}$, \\ RADU SPATARU $^{1,9}$, DANIEL OVIDIU COSTEA ${ }^{10,11}$, CIPRIAN TANASESCU ${ }^{8}$ and ANA MARIA DASCALU ${ }^{1,12}$
}

${ }^{1}$ Faculty of Medicine, 'Carol Davila' University of Medicine and Pharmacy, 020011 Bucharest; ${ }^{2}$ ICU II Toxicology, Clinical Emergency Hospital, 014461 Bucharest; ${ }^{3}$ Military Medical Research Center, 010919 Bucharest;

${ }^{4}$ Faculty of Medicine, The University of Medicine and Pharmacy of Craiova, 200349 Craiova;

${ }^{5}$ Fourth Surgery Department, Emergency University Hospital Bucharest, 050098 Bucharest; ${ }^{6}$ General Surgery,

Emergency Clinical Hospital 'Prof. Dr. Bagdasar Arseni', 041915 Bucharest; ${ }^{7}$ Department of Surgery, 'Sf. Pantelimon' Emergency Clinical Hospital, 021659 Bucharest; ${ }^{8}$ Third Department, Faculty of Medicine, 'Lucian Blaga' University of Sibiu, 550169 Sibiu; ${ }^{9}$ Department of Pediatric Surgery, Emergency Clinic Hospital for Children 'Marie S. Curie', 077120 Bucharest;

${ }^{10}$ Faculty of Medicine, Ovidius University, 900470 Constanta; ${ }^{11}$ First Surgery Department, Emergency County Hospital, 900591 Constanta; ${ }^{12}$ Ophthalmology Department, Emergency University Hospital Bucharest, 050098 Bucharest, Romania

Received April 29, 2021; Accepted June 3, 2021

DOI: $10.3892 /$ etm.2021.10417

\begin{abstract}
Suspicion of lead poisoning is confirmed by its concentration in blood and protoporphyrin red blood cells. At low concentrations, lead influences the synthesis of the heme in the sense of lowering it. Acute and chronic lead intoxication is extremely polymorphic in regards to its clinical manifestations, with digestive, hematological, cardiovascular, renal hepatic and neurological features. The aim of the study was to evaluate the presence of lead in human whole blood and urine harvested before and during chelation treatment in the case of lead poisoning. An atomic absorption spectroscopic method for the analysis of lead was developed using graphite furnace atomic absorption spectrophotometer (GF-AAS), Varian Spectra AA-880 with a hollow cathode lead lamp and a deuterium lamp for background correction, coupled to a GTA-100 atomizer and a programmable sample dispenser. Standard calibration solutions were used for the range $10-100 \mu \mathrm{g} / 1$. The
\end{abstract}

Correspondence to: Dr Dragos Serban, Faculty of Medicine, 'Carol Davila' University of Medicine and Pharmacy, 37 Dionisie Lupu Street, 020011 Bucharest, Romania

E-mail: dragos.serban@umfcd.ro

Abbreviations: GF-AAS, graphite furnace atomic absorption spectrometry

Key words: lead toxicity, GF-AAS, biological samples, saturnine colic, acute abdominal pain linearity range was 10.0 to $100.0 \mu \mathrm{g} / \mathrm{l}$ with the correlation coefficient of 0.999 . We established that the method can be applied for the determination of lead in whole blood and urine, and the results obtained are useful for monitoring chelation therapy in cases of acute lead poisoning, a neglected cause of abdominal colic pain in an emergency situation.

\section{Introduction}

Lead intoxication is an environmental health problem, with extremely severe consequences upon the human body (1). Acute lead poisoning manifests clinically with intense acute abdominal pain, being a challenging diagnosis in emergency situations (2). Development a quick and reliable method for lead determination in blood and urine, is important in clinical practice, both in diagnostics, but also in monitoring chelating therapy.

The main sources of lead that result in lead contamination include: Paint; leaded petrol; drinking water; car batteries, cables, glass; printers with lead-based technology; manufacture and use of war ammunition $(3,4)$. In melters, the main danger is melting. The risk of exposure to lead increases with increasing temperature in industrial processes (5).

The main routes of absorption of lead are gastric and pulmonary. Gastric absorption in adults is about $10-15 \%$ of the total amount ingested and $40 \%$ in children. At the lung level it is absorbed at $\sim 50-70 \%$ of the inhaled dose. In organic form, lead from tetraethyl lead is also absorbed at the skin level (6). Inhalation absorption depends on the form of lead (vapors or particles). Approximately $90 \%$ of inhaled particulate lead is absorbed into the respiratory tract (7). Once absorbed, $99 \%$ is 
transported by the bloodstream and binds to hemoglobin in red blood cells $(2,5)$.

The distribution is completed in three compartments, namely in the blood compartment, mineralized tissues (bones, teeth) and soft tissues (kidneys, bone marrow, liver and brain). Lead in the blood is distributed at a percentage of $99 \%$ in erythrocytes and $1 \%$ in plasma and is available for transport to tissues. The blood concentration does not reflect the actual amount of lead in the body, but $\sim 90 \%$ is stored in tissues, with a maximum half-life of $\leq 30$ years (8). Because lead is mobilized from these tissues, individuals who have been exposed may have high concentrations of lead, from a few months to several years from the time of exposure cessation (7). The level of lead in the blood, a traditional indication of absorption, reflects only recent exposure as the half-life in the blood is 36 days (3). In individuals with chronic exposure, there is a small correlation between a level once determined at a control and the cumulative absorption index or loading of the lead organism.

Suspicion of lead poisoning is confirmed by its concentration in blood and protoporphyrin red blood cells. At low concentrations, lead influences the synthesis of the heme in the sense of lowering it. Due to the fact that the level of erythrocyte protoporphyrin is not pathognomonic in children at levels of approximately $25 \mu \mathrm{g} / \mathrm{dl}$, the best method remains to determine the level of blood lead $(9,10)$. Lead binds to the sulfur groups of many enzymes by inactivating them. Lead poisoning has a multisystemic, hematological, cardiovascular, renal, hepatic, digestive and neurotoxic impact (5). Acute intoxication at blood levels $>50 \mu \mathrm{g} / \mathrm{dl}$ causes saturnine colic, and biochemical dosing of lead when there is clinical suspicion is extremely important in emergency situation, in the differential diagnosis of acute abdomen, to avoid white laparotomies in patients with severe abdominal colic pain (11).

This work aims to present a method of determination for lead in blood and urine using graphite furnace atomic absorption spectrometry (GF-AAS) with a background correction. Atomic absorption spectrometry with graphite furnace atomization (GF-AAS) is a leading technique in analytical chemistry as a routine low-level assay for lead and other heavy metals, for a wide variety of sample types (12).

\section{Materials and methods}

Instrumentation. Lead analysis was performed using a graphite furnace atomic absorption spectrophotometer (GF-AAS) Varian Spectra AA-880, with a hollow cathode lamp (Agilent Technologies, Inc.) and a deuterium lamp (Agilent Technologies, Inc.) for background correction, coupled to a GTA-100 atomizer and a programmable sample dispenser (Varian). Addition instrumentation included: A monochromator (fully automatic computer-controlled Czerny-Tuner micromotor, focal length $0.33 \mathrm{~mm}$; automatic sample dispenser PSD Varian with 54 positions for samples, standards, modifiers, quality control and buffer, maximum injected quantity $100 \mu \mathrm{l}$, injection precision $0.2 \mu \mathrm{l}$, automatic dilution and mixing, automatic re-injection of samples); Neslab CFT 33 water cooler for graphite oven working at temperature $15-25^{\circ} \mathrm{C}$; a nitrogen generator (Dominik Hunter) (purity, 99.999\%); EBA 200 Hettich Centrifuge, Eppendorf automatic pipette $1,000 \mu 1$. Biochemical parameters were
Table I. Working parameters for determining lead by GF-AAS.

\begin{tabular}{|c|c|c|}
\hline No. & Parameter & Method \\
\hline 1. & Injection mode & Automated dilution \\
\hline 2. & Calibration mode & Concentration \\
\hline 3. & Type of measurement & Peak height \\
\hline 4. & Replicate standard & 3 \\
\hline 5. & Replicate sample & 3 \\
\hline 6. & Smoothing & 9 \\
\hline 7. & Wavelength & $283.3 \mathrm{~nm}$ \\
\hline 8. & Slit & 0.5 \\
\hline 9. & Lamp current & $10 \mathrm{~mA}$ \\
\hline 10. & Background correction & Yes \\
\hline 11. & Standard 1 & $10 \mu \mathrm{g} / \mathrm{l}$ \\
\hline 12. & Standard 2 & $20 \mu \mathrm{g} / \mathrm{l}$ \\
\hline 13. & Standard 3 & $50 \mu \mathrm{g} / 1$ \\
\hline 14. & Standard 4 & $100 \mu \mathrm{g} / 1$ \\
\hline 15. & Recalibration rate & 30 \\
\hline 16. & Calibration algorithm & New rational \\
\hline 17. & Total volume & $15 \mu 1$ \\
\hline 18. & Sample volume & $10 \mu 1$ \\
\hline 19. & Dilution coefficient & 2 \\
\hline
\end{tabular}

GF-AAS, graphite furnace atomic absorption spectrometry.

determined from blood on the Vitros 650 System (Ortho Clinical Diagnostics) and complete blood count on a Celltac-F Hematology Analyzer (Nihon Kohden).

Samples and reagents. Biological samples (20 urine samples and 20 blood samples) were collected during hospitalization (23 days) from a patient admitted to the Intensive Care II Unit, Toxicology Department within the Bucharest Emergency Clinical Hospital. Written informed consent was obtained after the study protocol was previously discussed and explained to the patient.

All chemicals were of analytical or certified-reagent grades. Lead standard solution Certipur ${ }^{\circledR}$ (Merck) $(1,000 \mathrm{mg} / \mathrm{l} \mathrm{Pb})$ was used. A lead stock solution $(100 \mu \mathrm{g} / \mathrm{l})$ was prepared daily in $0.01 \%$ nitric acid. Concentrated nitric acid (Lach-Ner), with a lead content $(<0.00005 \%)$ below the GF-AAS detection limit, was used. Solutions were prepared with grade doubly distilled, de-ionized water in polypropylene calibrated flasks. The required volumes were measured with air displacement pipettes (Eppendorf Research plus Models) with premium grade polypropylene tips. All glassware was cleaned with acid and rinsed thoroughly with distilled or unionized water before use.

Blood samples. Sodium heparin (Lilly) with a lead content below the GF-AAS detection limit was used. For analysis, $200 \mu \mathrm{l}$ of blood was mixed together with $800 \mu 15 \%$ anti-foam B (Sigma-Aldrich; Merck KGaA) solution and 1,000 $\mu 11.6 \mathrm{M}$ solution of $65 \% \mathrm{HNO}_{3}$. They were allowed to stabilize for $10 \mathrm{~min}$ and then centrifuged for $5 \mathrm{~min}$ at $2,884 \mathrm{x}$ g relative centrifugal force (RCF). The supernatant was collected and 
Table II. Furnace GTA-100 Varian operating conditions for lead measurements.

\begin{tabular}{cccccc}
\hline Step Temperature $\left({ }^{\circ} \mathrm{C}\right)$ & Time $(\mathrm{sec})$ & Flow (liters/min) & Gas type & Read & Signal storage \\
\hline 40 & 1.0 & 3.0 & Normal & No & No \\
85 & 5.0 & 3.0 & Normal & No & No \\
95 & 40.0 & 3.0 & Normal & No & No \\
120 & 10.0 & 3.0 & Normal & No & No \\
120 & 5.0 & 3.0 & Normal & No & No \\
400 & 5.0 & 3.0 & Alternate & No & No \\
400 & 1.0. & 3.0 & Alternate & No & No \\
400 & 2.0 & 0.0 & Alternate & No & Yes \\
2,100 & 1.0 & 0.0 & Alternate & Yes & Yes \\
2,100 & 2.0 & 0.0 & Alternate & Yes & Yes \\
2,100 & 3.0 & 3.0 & Normal & No & Yes \\
40 & 2.0 & 3.0 & Normal & No & No \\
40 & 5.0 & 0.0 & Normal & No & No \\
\hline
\end{tabular}

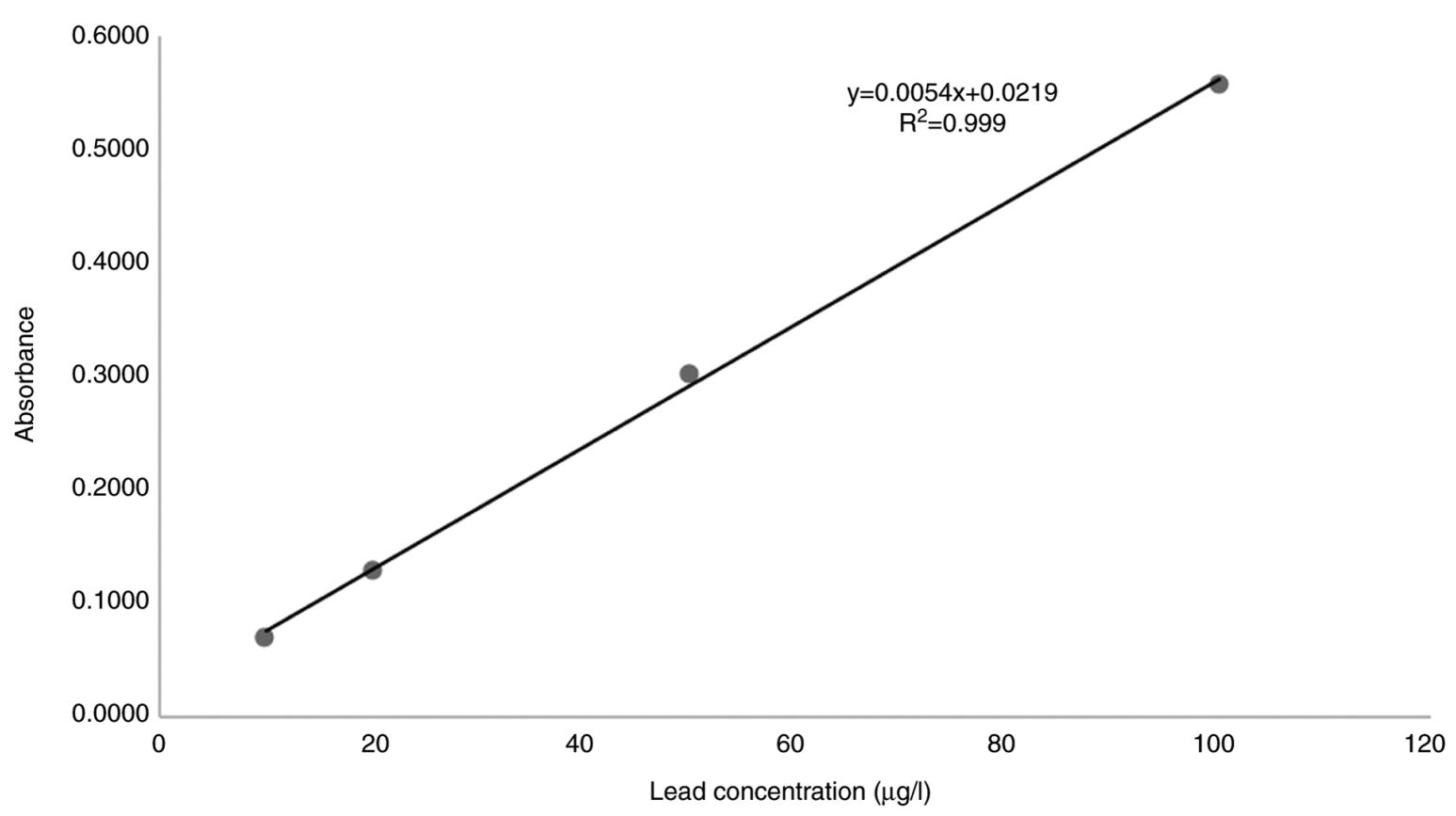

Figure 1. The linear regression curve for the determination of lead etalon model.

analyzed on the graphite furnace atomic absorption (GF-AAS) system.

Urine samples. A volume of $9 \mathrm{ml}$ of urine was treated with $1 \mathrm{ml}$ of $65 \% \mathrm{HNO}_{3}$. The sample was allowed to stabilize for $20 \mathrm{~min}$ and then centrifuged for $10 \mathrm{~min}$ at 2,884 $\mathrm{x}$ g relative centrifugal force $(\mathrm{RCF})$. The supernatant was then analyzed on the GF-AAS system. There were several trials using different working parameters, to reach optimum conditions (Table I).

\section{Results}

Optimization of the working parameters. The atomization temperature was established by varying the atomization temperature between 1,600 and $2,100^{\circ} \mathrm{C}$. As expected, the lead signal increased with the increase in the atomization temperature up to $2,000^{\circ} \mathrm{C}$. For temperatures $>2,100^{\circ} \mathrm{C}$, the signals remained almost constant, indicating that maximum atomization efficiency can be achieved in this range (Table II).

The application of the optimized temperature program made possible elimination of the whole matrix of the sample before the atomization step, as confirmed by the low background signals observed in the measurement of lead (13-15). To determine the performance parameters for the method (linearity, accuracy, precision and robustness) standard calibration solutions were used in the concentration range $10-100 \mu \mathrm{g} / 1$ (14). The detection and quantification limits were established according to ICH (International Conference on Harmonization) recommendations $(16,17)$. 
Table III. Performance parameters of the linear regression equation.

\begin{tabular}{|c|c|c|c|c|c|c|c|c|c|}
\hline Denomination & $\begin{array}{l}\text { Conc. } \\
(\mu \mathrm{g} / \mathrm{l})\end{array}$ & Abs & $\begin{array}{l}\text { Media } \\
\text { Abs }\end{array}$ & $\begin{array}{c}\text { Abs } \\
\text { without } \\
\text { blank }\end{array}$ & $\begin{array}{l}\mathrm{R}^{2} \text { coefficient } \\
\text { of determination }\end{array}$ & Slope & $\begin{array}{l}\text { Standard } \\
\text { deviation } \\
\text { of slope } \\
\text { (STD) }\end{array}$ & $\begin{array}{l}\text { Ordinate } \\
\text { at origin b }\end{array}$ & $\begin{array}{l}\text { Standard } \\
\text { deviation } \\
\text { (STD) of } \\
\text { the ordinate } \\
\text { at origin }\end{array}$ \\
\hline Blank & 0 & $\begin{array}{l}0.0086 \\
0.0091 \\
0.0079\end{array}$ & 0.0085 & & 0.9986 & 0.0054 & 0.0001 & 0.0219 & 0.0068 \\
\hline Standard 1 & 10 & $\begin{array}{l}0.0726 \\
0.0839 \\
0.0799\end{array}$ & 0.0788 & 0.0703 & & & & & \\
\hline Standard 2 & 20 & $\begin{array}{l}0.1393 \\
0.1363 \\
0.1406\end{array}$ & 0.1387 & 0.1302 & & & & & \\
\hline Standard 3 & 50 & $\begin{array}{l}0.2943 \\
0.3151 \\
0.3190\end{array}$ & 0.3095 & 0.3009 & & & & & \\
\hline Standard 4 & 100 & $\begin{array}{l}0.5744 \\
0.5630 \\
0.5589\end{array}$ & 0.5654 & 0.5569 & & & & & \\
\hline
\end{tabular}

Abs, absorbance; conc., concentration.

Table IV. Validation parameters.

\begin{tabular}{lc}
\hline Cation & $\mathrm{Pb}^{2+}$ \\
\hline Linearity range & $10-100 \mu \mathrm{g} / 1$ \\
Regression equation & $\mathrm{y}=0.0054 \mathrm{x}+0.0219$ \\
Correlation coefficient $\left(\mathrm{R}^{2}\right)$ & 0.9990 \\
Intercept & 0.0219 \\
Slope & $0.0054 \mu \mathrm{g} / 1$ \\
SE of intercept & 0.0068 \\
SD of intercept & 0.02633572 \\
LOD & $4.15 \mu \mathrm{g} / 1$ \\
LOQ & $12.59 \mu \mathrm{g} / 1$ \\
\hline
\end{tabular}

SE, standard error; SD, standard deviation; LOD, limit of detection; LOQ, limit of quantification.

A linear relationship was found between the absorbance at $283.3 \mathrm{~nm}$ and the concentration of lead in the range of 10.0 to $100 \mu \mathrm{g} / 1$. The representative linear equation was $\mathrm{y}=0.0054 \mathrm{x}+0.0219$ where: $\mathrm{y}$ is the absorbance, $\mathrm{x}$ is the lead concentration $(\mu \mathrm{g} / \mathrm{l})$, calculated by the least squares method. The regression coefficient $\left(\mathrm{R}^{2}\right)$ standard curve was 0.9990 (Fig. 1) indicating good linearity.

The performance parameters of the linear regression equation are presented in Table III. The parameters of the GF-AAS analysis method of lead are presented in Table IV, and the calibration curve can be observed in Fig. 1. The limit of detection (LOD) and the limit of quantification (LOQ) were detected for the method based on the standard deviation of 6 readings of the standard solution blank and on the slope of the analytical curve (Table III).

LOD is the lowest concentration of an analyte that can be detected while LOQ is defined as the lowest concentration of an analyte that can be determined at the acceptable level of precision and accuracy and were calculated according to the formula below: $\mathrm{LOD}=3.3 \mathrm{x}$ (SD of intercept/slope) and LOQ $=10 x$ (SD of intercept/slope) (Table IV).

The accuracy of the assays (BIAS), expressed as the consistency between the real value and the analytical result, was calculated using three sources of blank matrix samples fortified at each level of concentration analyzed in duplicate. The calculated coefficient of variance (CV\%) which describes the precision of the analytical method is shown in Table V. The CV\% did not exceed $15 \%$ at each concentration and the BIAS was $<15 \%$ at each level of concentration, which ensured a superior trust grade for each determination using this method. In other words, the difference between the real value and the determined value of concentration was minimal.

Clinical application. Lead level monitoring in humans is of great importance due to its high toxicity. In order to detect lead in whole blood, the authors developed a method using GF-AAS, for quantifying the lead level in blood which can be used for monitoring lead levels during chelation treatment time. The permissible concentration of lead in the blood is up to $20 \mu \mathrm{g} / \mathrm{dl}$, and in urine $\leq 40 \mu \mathrm{g} / \mathrm{l}$.

Acute lead poisoning manifests with acute abdominal pain, nausea and vomiting, being a neglected cause in the differential diagnosis of acute surgical abdomen. A careful anamnesis, 
Table V. The performance parameters of the analytical method for lead determination.

\begin{tabular}{|c|c|c|c|c|c|c|}
\hline Level & $\begin{array}{c}\text { Standard solution } \\
\text { concentration } \\
\mu \mathrm{g} / \mathrm{ml}\end{array}$ & $\begin{array}{c}\text { Measured } \\
\text { concentration } \\
\mu \mathrm{g} / \mathrm{ml}\end{array}$ & $\begin{array}{c}\text { Average measured } \\
\text { concentration } \\
\mu \mathrm{g} / \mathrm{ml}\end{array}$ & $\begin{array}{l}\text { Standard } \\
\text { deviation }\end{array}$ & BIAS & $\mathrm{CV} \%$ \\
\hline \multirow[t]{3}{*}{1} & 10 & 9.41 & \multirow[t]{3}{*}{10.56} & \multirow[t]{3}{*}{1.06} & -5.90 & \multirow[t]{3}{*}{10.04} \\
\hline & 10 & 11.50 & & & 15.00 & \\
\hline & 10 & 10.76 & & & 7.60 & \\
\hline \multirow[t]{3}{*}{2} & 20 & 21.78 & \multirow[t]{3}{*}{21.67} & \multirow[t]{3}{*}{0.41} & 8.90 & \multirow[t]{3}{*}{1.89} \\
\hline & 20 & 21.22 & & & 6.10 & \\
\hline & 20 & 22.02 & & & 10.10 & \\
\hline \multirow[t]{3}{*}{3} & 50 & 50.53 & \multirow[t]{3}{*}{53.34} & \multirow[t]{3}{*}{2.46} & 1.06 & \multirow[t]{3}{*}{4.61} \\
\hline & 50 & 54.38 & & & 8.76 & \\
\hline & 50 & 55.11 & & & 10.22 & \\
\hline \multirow[t]{3}{*}{4} & 100 & 102.47 & \multirow[t]{3}{*}{100.81} & \multirow[t]{3}{*}{1.49} & 2.47 & \multirow[t]{3}{*}{1.48} \\
\hline & 100 & 100.36 & & & 0.36 & \\
\hline & 100 & 99.60 & & & -0.40 & \\
\hline
\end{tabular}

BIAS, accuracy of the assays; CV\%, coefficient of variance.

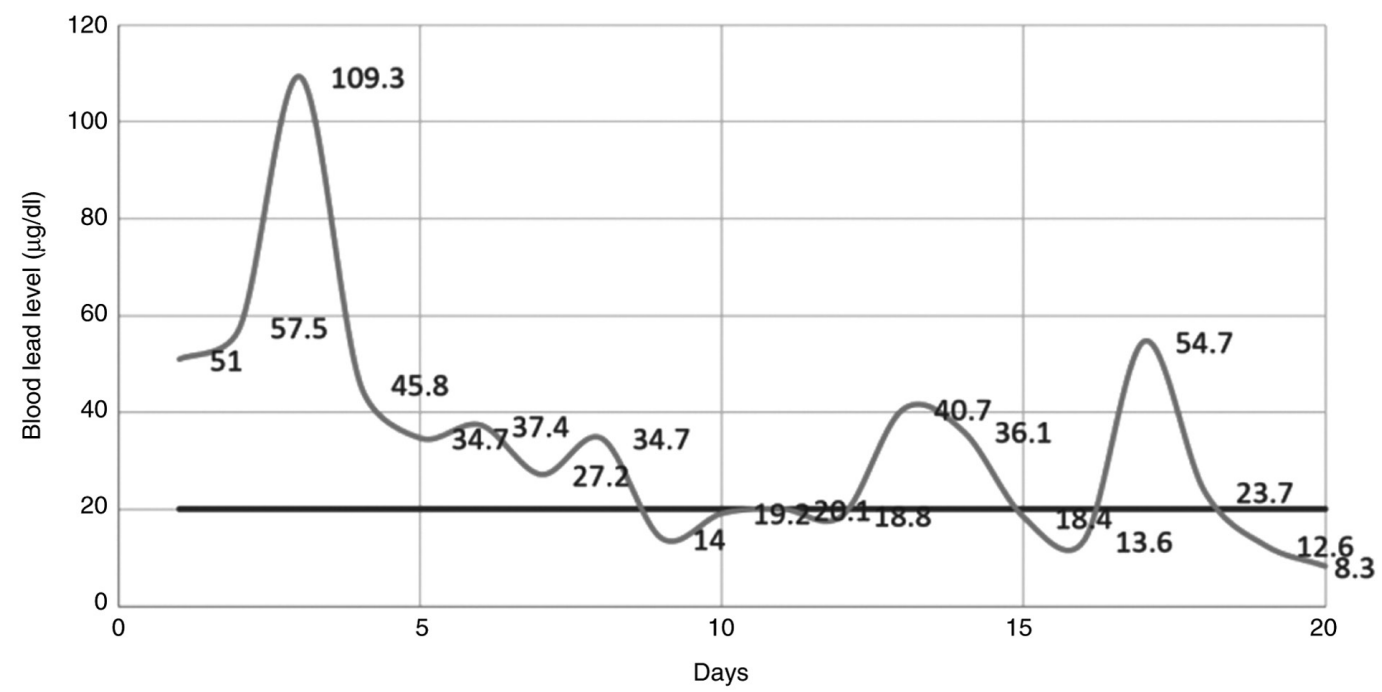

Figure 2. Variation of lead levels in whole blood, measured by the presented GF-AAS technique, during chelating treatment in a case of lead intoxication. GF-AAS, graphite furnace atomic absorption spectrometry.

revealing previous toxicological history, occupational risk or hobbies that might be associated with lead exposure, may reveal important information, but it may not be always accurate, due to patient multiple comorbidities, ignorance of the possible toxic risk or neuropsychiatric disorders. A frequent associated condition is anemia, due to the increased fragilization of the erythrocyte membranes and hemolysis. In suspect cases or patients with a non-conclusive clinical and imagistic exam, a prompt and reliable determination of lead concentration in blood is extremely important to avoid 'white' laparotomies and associated perioperative morbidity.

The therapeutic approach is based on sustaining vital functions and increased lead elimination through urine. Chelating therapy is usually initiated when lead concentration in blood is more than $50 \mu \mathrm{g} / \mathrm{dl}$, due to the possible dangerous side effects.
The most commonly used chelating agents in lead intoxication include: Dimercaptosuccinic acid, dimercaprol and $\mathrm{CaNa}_{2}$ EDTA. Among the current drawbacks of the chelation therapy, the clinician must take into account the hepatotoxicity and nephrotoxicity, essential metal loss, headaches, nausea, arrythmias, hypotension or hypertension, bone marrow depression, convulsions or even cardio-respiratory arrest $(17,18)$. Another aspect is the redistribution of the lead among the body compartments, which may generate important fluctuation of blood and urine concentration during the first days of therapy. Prolonged treatment with $\mathrm{CaNa}_{2}$ EDTA results in depletion of essential metals, especially $\mathrm{Zn}, \mathrm{Cu}$ and $\mathrm{Mn}$, requiring oral $\mathrm{Zn}$ supplementation (17).

Chelating therapy requires close monitorization and advanced medical skill (5). In our department, patients admitted for acute lead poisoning are closely followed 
up by daily laboratory tests including: Hemoleucogram, transaminase, urea, creatinine, electrolytes $\left(\mathrm{Na}^{+}, \mathrm{K}^{+}, \mathrm{Ca}^{++}\right)$, as well as lead concentration in the blood and urine. The optimized method based on GF-AAS technique proves to be useful for monitoring chelation therapy in the cases of acute lead poisoning. It allows a close follow-up of the dynamic concentrations of lead in the blood and urine, as presented in Fig. 2.

\section{Discussion}

Saturnine colic is an infrequent cause of differential diagnosis of acute abdomen, which may appear in cases of acute lead poisoning, with blood lead levels exceeding $50-80 \mu \mathrm{g} / \mathrm{dl}(2,19-22)$. If undiagnosed, it can lead to avoidable surgeries, by mimicking acute appendicitis, perforated ulcer, acute pancreatitis or bowel obstruction (21-23). The abdominal pain is intense, colliquative, in the periumbilical area, resistant to usual antispastics $(2,20-22)$. The pain diminishes at profound palpation of the abdomen, with no tenderness or contracture, being a key element of differential diagnosis with surgical acute abdomen. Other signs and symptoms are anorexia, nausea, vomiting, constipation or very rarely, diarrhea $(23,24)$. Radiological abdominal exam shows hydroaeric images, with alternative sectors of spastic and moderate dilated intestinal loops. The patient may experience transient increased blood pressure, which comes back to normal after ceasement of abdominal pain with chelating therapy. Oliguria, increased serum urea and leukocytosis may be associated with acute poisoning (19).

It is well known that exposure to lead causes dose-dependent decreases in heme synthesis by inhibiting the enzyme $\delta$-aminolaevulinic acid dehydrase ( $\delta$-ALAD). Hematologic tests such as hemoglobin concentration may suggest toxicity, but this is not specific for lead (25). The higher the level of blood lead levels, the lower the hemoglobin in the blood and the level of erythrocytes due to the increase in lead-induced membrane fragility resulting in the development of anemia (26). The toxicity of lead on the human hematological system has been established in numerous studies. Other effects of lead on the hematological system are decreased activity of erythrocyte enzymes (pyrimidine 5'-nucleotidase) and altered levels of plasma erythropoietin (27).

The effects of acute and chronic lead intoxication upon the nervous system have been studied for 100 years. Lead is a highly neurotoxic element, both for central nervous system and peripheric nerves. Even concentrations below $10 \mu \mathrm{g} / \mathrm{dl}$, in children, are inversely correlated with the intelligence quotient (IQ). There are well-defined clinical features encountered in both adults and children: Decreased learning ability, memory loss, cognitive deterioration, reduced neural signaling and demyelination. At blood levels $>70 \mu \mathrm{g} / \mathrm{dl}$ in children and $>100 \mu \mathrm{g} / \mathrm{dl}$ in adults lead toxicity is increased and may cause paresis or paralysis and saturnine encephalopathy, with sudden seizures, changes in consciousness, coma and death $(28,29)$. Furthermore, several studies have confirmed the pathogenic role of lead intoxication in Alzheimer disease and glaucoma, by increasing the tissular oxidative stress, through depletion of glutathione and thiol pools, as well as by disrupting the antioxidant defense system (30-35). Several studies revealed that probiotics may be useful for alleviation and treatment of lead toxicity, reducing the specific side-effects in heavily polluted areas $(36,37)$. Accidental or occupational lead intoxication is an important public health problem, causing a significant burden especially in low- and middle-income countries (38). The Institute for Health Metrics and Evaluation (IHME) estimated that in 2017, lead exposure accounted for 1.06 million deaths and 24.4 million years of healthy life lost worldwide due to long-term effects on health (39). The most severe include the neurologic and cardiovascular effects of acute or chronic lead poisoning: $63.2 \%$ of the global burden of idiopathic developmental intellectual disability, $10.3 \%$ of the global burden of hypertensive heart disease, $5.6 \%$ of the global burden of the ischemic heart disease and $6.2 \%$ of the global burden of stroke (40).

Graphite furnace atomic absorption spectrometry (GF-AAS) is increasingly becoming the method of choice for the determination of lead and other heavy metals in blood and urine, as well as in other biological products (40-43), with several improvements developed in time to increase its power of detection and determination for lower concentrations.

Whole blood lead levels are the most widely used and most generally accepted measure of absorbed dose. A repeatable, reliable, cost-efficient method is an important tool for lead intoxication screening and chelation therapy monitoring in clinical practice.

GF-AAS is simpler, less expensive, quicker and more accurate than neutron activation or emission spectrometric technique. The absorbance signals obtained for lead in the optimizing conditions presented ensures a well-defined profile and a low background (42-44).

The reported method shows high precision and accuracy, as well as a wide applicability in routine lead determination and research assays. The methods developed are valuable for clinical diagnostics and biological monitoring of work-related exposure.

\section{Acknowledgements}

Not applicable.

\section{Funding}

No funding was received.

\section{Availability of data and materials}

All data generated or analyzed during this study are included in this published article.

\section{Authors' contributions}

MST, GC, OA, ADS and DS were responsible for the conception and design of this study. DMP, CGS, CT, AMD, CDB, DOC and BS were responsible for the data collection and analysis. MST, GC, OA, CT and DS were in charge of drafting the manuscript. AMD, MC, ADS, DOC and RS revised critical perspectives for important intellectual content. The final version for publication was read and approved by all the authors. 


\section{Ethics approval and consent to participate}

Written informed consent was obtained after the study protocol was previously discussed and explained to the patient.

\section{Patient consent for publication}

Not applicable.

\section{Competing interests}

The authors declare that they have no competing interests.

\section{References}

1. Jaishankar M, Tseten T, Anbalagan N, Mathew BB and Beeregowda KN: Toxicity, mechanism and health effects of some heavy metals. Interdiscip Toxicol 7: 60-72, 2014.

2. Gopinath B, Kappagantu V, Mathew R and Jamshed N: Acute lead poisoning: A diagnostic challenge in the emergency department. BMJ Case Rep 14: e239740, 2021

3. Wani AL, Ara A and Usmani JA: Lead toxicity: A review. Interdiscip Toxicol 8: 55-64, 2015.

4. Maizlish N and Rudolph L: California adults with elevated blood lead levels, 1987 through 1990. Am J Public Health 83: 402-405, 1993.

5. Flora SJ and Pachauri V: Chelation in metal intoxication. In J Environ Res Public Health 7: 2745-2788, 2010.

6. Rădulescu A and Lundgren S: A pharmacokinetic model of lead absorption and calcium competitive dynamics. Sci Rep 9: 14225, 2019.

7. Internaţional Labor Organization (ILO): Encyclopaedia of Occupational Health and Safety. 4th edition. Stellman JM (ed) Geneva, 1998. https://www.ilo.org/global/publications/ilo-bookstore/order-online/multimedia/WCMS_PUBL_9221098184_EN/ lang--en/index.htm.

8. Rossi E: Low level environmental lead exposure-a continuing challenge. Clin Biochem Rev 29: 63-70, 2008.

9. Riva MA, Lafranconi A, D'orso MI and Cesana G: Lead poisoning: Historical aspects of a paradigmatic 'occupational and environmental disease'. Saf Health Work 3: 11-16, 2012.

10. Halmo L and Nappe TM: Lead Toxicity. [Updated 2020 Jul 10]. In: StatPearls [Internet]. Treasure Island (FL), StatPearls Publishing, Jan, 2021. https://www.ncbi.nlm.nih.gov/books/ NBK541097/.

11. Rolston DD: Uncommon sources and some unsual manifestations of lead poisoning in a tropical developing country. Trop Med Health 39: 127-132, 2011.

12. Tudosie MS, Danciulescu Miulescu R, Negulescu V, Ionica M, Stefan SD, Corlan G and Macovei R: Evaluation and modeling of pharmacokinetics of copper ion during hemodialysis. Farmacia 61: 53-65, 2013

13. Tudosie MS, Păun SC, Macovei R, Ionica M, Ardelean L and Macovei A: The role of the atomic absorption spectrometry in the study of blood lead levels and outlet dialysate lead levels for chronic kidney disease patients. Therapeutics Pharmacol Clin Toxicol 15: 211-215, 2011 .

14. Kelly RS, Lundh T, Porta M, Bergdahl IA, Palli D, Johansson AS Botsivali M, Vineis P, Vermeulen R, Kyrtopoulos SA, et al Blood erythrocyte concentrations of cadmium and lead and the risk of B-cell non-Hodgkin's lymphoma and multiple myeloma: A nested case-control study. PLoS One 8: e81892, 2013.

15. International Conference on Harmonization (ICH) of Technical Requirements for the Registration of Pharmaceuticals for Human Use-3AQ13a Validation of analytical procedures: Methodology, Geneva, Switzerland, 1997.

16. International Conference on Harmonization (ICH) of Technical Requirements for the Registration of Pharmaceuticals for Human Use-Q2(R1) Validation of analytical procedures: Text and methodology. Geneva, Switzerland, 2005.

17. Gracia RC and Snodgrass WR: Lead toxicity and chelation therapy. Am J Health Syst Pharm 64: 45-53, 2007.

18. Ferrero ME: Rationale for the successful management of EDTA chelation therapy in human burden by toxic metals. Biomed Res Int 2016: 8274504, 2016.
19. Kosnett MJ: 'Lead'. In Brent J (ed): Critical Care Toxicology: Diagnosis and Management of the Critically Poisoned Patient. Gulf Professional Publishing, 2005.

20. Shiri R, Ansari M, Ranta M and Falah-Hassani K: Lead poisoning and recurrent abdominal pain. Ind Health 45: 494-496, 2007.

21. Vossoughinia H,Pourakbar A,EsfandiariS and Sharifianrazavi M: Severe abdominal pain caused by lead toxicity without response to oral chelators: A case report. Middle East J Dig Dis 8: 67-72, 2016.

22. Spataru RI, Sirbu A and Sirbu D: Forensic ramifications in diagnosing and treating high forms of the Hirschsprung's disease. Rom J Leg Med 21: 105-110, 2013.

23. Tsai MT, Huang SY and Cheng SY: Lead poisoning can be easily misdiagnosed as acute porphyria and nonspecific abdominal pain. Case Rep Emerg Med 2017: 9050713, 2017.

24. Nicolli A, Mina GG, De Nuzzo D, Bortoletti I, Gambalunga A, Martinelli A, Pasqualato F, Cacciavillani M, Carrieri M and Trevisan A: Unusual domestic source of lead poisoning. Int J Environ Res Public Health 17: 4374, 2020.

25. Mărginean CO, Meliţ LE, Moldovan H, Lupu VV and Mărginean MO: Lead poisoning in a 16-year-old girl: A case report and a review of the literature (CARE compliant). Medicine (Baltimore) 95: e4916, 2016.

26. Hegazy AA, Zaher MM, Abd El-Hafez MA, Morsy AA and Saleh RA: Relation between anemia and blood levels of lead, copper, zinc and iron among children. BMC Res Notes 3: 133 , 2010.

27. NAS: 2013. Potential Health Risks to DOD Firing-Range Personnel from Recurrent Lead Exposure. Washington, DC: National Academy of Sciences, National Research Council. http://nap.edu/18249. Accessed February 19, 2020.

28. Kim Y, Yoo CI, Lee CR, Lee JH, Lee H, Kim SR, Chang SH, Lee WJ, Hwang $\mathrm{CH}$ and Lee YH: Evaluation of activity of erythrocyte pyrimidine 5'-Nucleotidase (P5N) in lead exposed workers: With focus on the effect on hemoglobin. Ind Health 40: 23-27, 2002.

29. Ellenhorn MJ: Ellenhorn's Medical Toxicology. Diagnosis and Treatment of Human Poisoning. 2nd edition. Williams \& Wilkins a Waverly Comp, Baltimore, MD, 1997.

30. Stanciu AE, Stanciu MM and Vatasescu RG: NT-proBNP and CA 125 levels are associated with increased pro-inflammatory cytokines in coronary sinus serum of patients with chronic heart failure. Cytokine 111: 13-19, 2018.

31. Fathabadi B, Dehghanifiroozabadi M, Aaseth J, Sharifzadeh G, Nakhaee S, Rajabpour-Sanati A, Amirabadizadeh A and Mehrpour O: Comparison of blood lead levels in patients with alzheimer's disease and healthy people. Am J Alzheimers Dis Other Demen 33: 541-547, 2018.

32. Wang W, Moroi S, Bakulski K, Mukherjee B, Weisskopf MG, Schaumberg D, Sparrow D, Vokonas PS, Hu H and Park SK: Bone lead levels and risk of incident primary open-angle glaucoma: The VA normative aging study. Environ Health Perspect 126: $087002,2018$.

33. Arnold C: Looking backward: Long-term lead exposure and risk of glaucoma. Environ Health Perspect 127: 54001, 2019.

34. Yuki K, Dogru M, Imamura Y, Kimura I, Ohtake Y and Tsubota K: Lead accumulation as possible risk factor for primary open-angle glaucoma. Biol Trace Elem Res 132: 1-8, 2009.

35. Jomova $\mathrm{K}$ and Valko $\mathrm{M}$ : Advances in metal-induced oxidative stress and human disease. Toxicology 283: 65-87, 2011.

36. Bhattacharya S: Probiotics against alleviation of lead toxicity: Recent advances. Interdiscip Toxicol 12: 89-92, 2019.

37. Radu N, Roman V and Tanasescu C: Biomaterials obtained from probiotic consortia of microorganisms. Potential applications in regenerative medicine. Mol Crystals Liquid Crystals 628: 115-123, 2017.

38. Kordas K, Ravenscroft J, Cao Y and McLean EV: Lead exposure in low and middle-income countries: Perspectives and lessons on patterns, injustices, economics, and politics. Int J Environ Res Public Health 15: 2351, 2018.

39. Valko M, Jomova K, Rhodes CJ, Kuča K and Musílek K: Redoxand non-redox-metal-induced formation of free radicals and their role in human disease. Arch Toxicol 90: 1-37, 2016.

40. World Health Organization (WHO): Lead poisoning and health August 23, 2019. https://www.who.int/news-room/fact-sheets/ detail/lead-poisoning-and-health. Accessed February 15, 2021.

41. Horng CJ, Tsai JL, Horng PH, Lin SC, Lin SR and Tzeng CC: Determination of urinary lead, cadmium and nickel in steel production workers. Talanta 56: 1109-1115, 2002 
42. Ivanenko NB, Solovyev ND, Ivanenko AA and Ganeev AA: Application of Zeeman graphite furnace atomic absorption spectrometry with high-frequency modulation polarization for the direct determination of aluminum, beryllium, cadmium, chromium, mercury, manganese, nickel, lead, and thallium in human blood. Arch Environ Contam Toxicol 63: 299-308, 2012.

43. Zhong WS, Ren T and Zhao LJ: Determination of Pb (Lead), $\mathrm{Cd}$ (Cadmium), $\mathrm{Cr}$ (Chromium), $\mathrm{Cu}$ (Copper), and $\mathrm{Ni}$ (Nickel) in Chinese tea with high-resolution continuum source graphite furnace atomic absorption spectrometry. J Food Drug Anal 24: 46-55, 2016.
44. Pozzatti M, Borges RA, Dessuy MB, Vale MGR and Welz B: Determination of cadmium, chromium and copper in vegetables of the Solanaceae family using high-resolution continuum source graphite furnace atomic absorption spectrometry and direct solid sample analysis. Anal Methods 9: 329-337, 2017. 